\title{
Effects of Intra-Arterial Infusion of Insulin on Control of Forearm Vascular Resistance in Normotensive and Hypertensive Subjects
}

\author{
Tsutomu Imaizumi
}

\begin{abstract}
In this article, I will review the recent progress in the relationship between hyperinsulinemia and control of vascular resistance. I particularly focus on effects of intra-arterial infusion of insulin on control of resting forearm vascular resistance and on vascular reactivity to vasoconstrictor agents in normotensive and hypertensive subjects. In conclusion, the physiological levels of local hyperinsulinemia may decrease resting forearm vascualr resistance in some normotensive subjects but not in all. Insulin-induced vasodilation may be due to the production of prostacyclin but not due to nitric oxide. Hyperinsulinemia attenuates vasoconstriction induced by phenylephrine and angiotensin II in normotensive subjects. Although acute intra-venous infusion of insulin activates the sympathetic nerve system, it may not elevate blood pressure in normotensive subjects possibly due to above mentioned anti-vasoconstrictor effects of insulin. In contrast, insulin-induced anti-vasoconstrictor mechanisms may be lost in hypertensive subjects, which may result in hypertension. (Hypertens Res 1996; 19 Suppl. I: S47-S50)
\end{abstract}

Key Words: insulin, forearm blood flow, vascular reactivity, prostacyclin, nitric oxide

Hypertension is associated with insulin-resistance or hyperinsulinemia $(1,2)$. It is postulated that hyperinsulinemia may contribute to hypertension via several mechanisms (3). Although acute hyperinsulinemia activates sympathetic nerve activity $(4,5)$, it does not elevate blood pressure in normotensive humans $(5,6)$. To explain this paradox, several investigators including us reported that insulin has vasodilating effects $(7,8)$, and that insulin decreases vasoreactivity to pressor agents $(9,10)$. In this review article, I focus on the effects of intra-arterially infused insulin on control of forearm vascular resistance.

\section{Effects of Intra-Venous Insulin Infusion}

Insulin stimulates $\mathrm{Na}^{+}-\mathrm{H}^{+}$exchanges and increases intracellular sodium and calcium concentrations of the vascular smooth muscle (11). Increases in intracellular calcium concentration would increase vascular resistance and enhance vascular reactivity to pressor agents. However, previous reports regarding the effects of insulin on vascular resistance are conflicting in humans $(8,12)$. Some reported increased, some no changes, and others decreased vascular resistance in the arm and leg with intravenous insulin using the euglycemic clamp method. The reported results of the effects of intravenous insulin on vasoreactivity to pressor stimuli are also conflicting. The results of intravenous insulin should be interpreted with caution, because insulin alters sympathetic tone $(4,5)$ by acting on the central nervous system.

\section{Effect of Intra-Arterial Infusion of Insulin on Resting Forearm Vascular Resistance}

It has been reported that intra-arterial infusion of insulin did not alter or slightly decreased forearm vascular resistance in normotensive subjects (13-15). We studied effects of intra-arterial infusion of insulin at $0.15 \mathrm{mU} / \mathrm{kg} / \mathrm{min}$ for $15-20 \mathrm{~min}$ on forearm blood flow in young healthy humans (mean age, 20.4 years) (9). Insulin infusion increased the local insulin level to about $120 \mu \mathrm{u} / \mathrm{ml}$ without changes in blood pressure and increased forearm blood flow in 4 , did not change in 4 , and decreased in 2 out of 10 subjects. Overall, insulin increased forearm blood flow from 4.4 to $5.6 \mathrm{ml} / \mathrm{min} / 100 \mathrm{ml}$ but this increase was not statistically significant. In another set of experiment in young healthy subjects, the overall increase in forearm blood flow was by $20 \%$. With the intra-arterial infusion method, systemic effects of insulin were excluded because the systemic level of insulin was $11 \mu \mathrm{u} / \mathrm{ml}$. Thus, it is likely that acute hyperinsulinemia may increase forearm blood flow in some but not in all and the vasodilating effects of insulin may be rather small.

\section{Effects of Insulin on Vasoreactivity}

Previous studies with intra-venous insulin by the use 
Control

a) Before Insulin
5

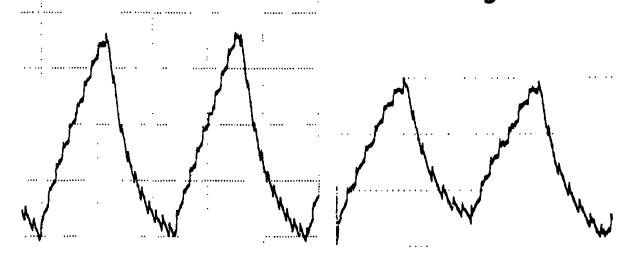

$\mathrm{FBF}\left(\mathrm{ml} \cdot \mathrm{min}^{-1} 100 \mathrm{ml}^{-1}\right)$
(2.8)
$\mathrm{AgII}(\mathrm{ng} / \mathrm{min})$

10

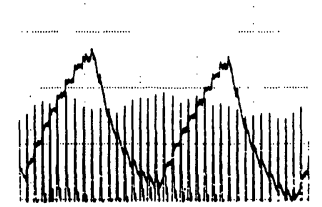

(2.2)
20

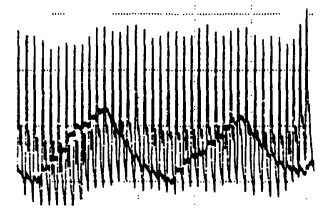

(1.2)

b) During Insulin

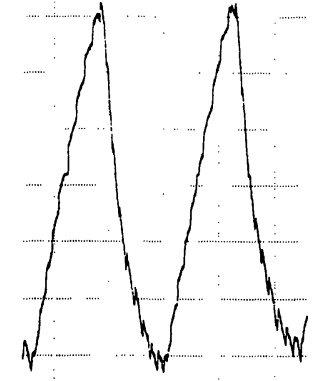

(7.3)

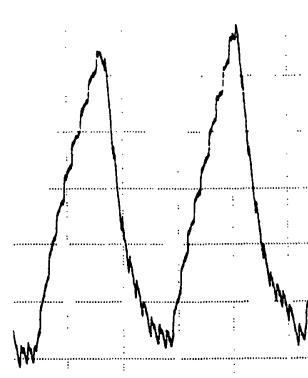

(6.4)

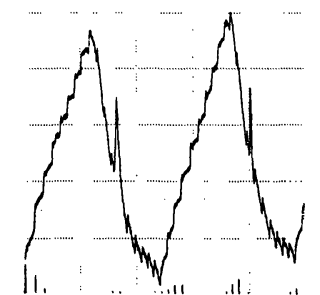

(6.0)

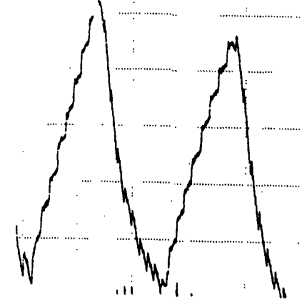

(5.0)

Fig. 1. Representative plethysmographic recordings show changes in forearm blood flow (FBF) during intra-arteral infusion of angiotensin II (Ang II) at graded doses before and during simultaneous intra-arterial infusion insulin. Angiotensin caused progressive decreases in forearm blood flow. Note that the baseline blood flow was significantly greater during insulin infusion and that decreases in forearm blood flow in response to phenylephrine were smaller during insulin infusion than before insulin infusion.

of the euglycemic clamp method demonstrated that insulin decreased or did not alter vascular reactivity to vasoconstricting stimuli $(16,17)$. However, Gans et al. recently reported that intravenous insulin augmented blood pressure response to norepinephrine but not to angiotensin II (18). Thus, reported results are conflicting. We examined whether local hyperinsulinemia during intra-arterial infusion of insulin altered vascular reactivity to phenylephrine and angiotensin II in young healthy subjects (9). Representative recordings are shown in Fig. 1. Before insulin infusion, angiotensin II caused dose-dependent decreases in forearm blood flow without changes in blood pressure. Thus, angiotensin II caused vasoconstriction dose-dependently. In this particular subject insulin infusion greatly increased resting forearm blood flow from 3.8 to 7.3 $\mathrm{ml} / \mathrm{min} / 100 \mathrm{ml}$ and attenuated angiotensin II-induced vasoconstriction. Pooled data are shown in Fig. 2. Insulin infusion slightly decreased resting forearm vascular resistance (not statistically significant) and attenuated vasoconstriction in response to phenylephrine and angiotensin II in young healthy subjects. We also examined vasoconstrictor responses to phenylephrine and angiotensin II in young hypertensive subjects (19). Representative recordings are shown in Fig. 3. Insulin infusion slightly increased resting forearm blood flow. In contrast to normotensive subjects, angiotensin II-induced forearm vasoconstriction was similar before and during insulin infusion. Pooled data are shown Fig. 4. Insulin did not alter vasoconstriction in response to phenylephrine and angiotensin II. Thus, in hypertensive subjects, anti-vasoconstricting effects of insulin were lost. We suggest that the balance between the pressor and depressor effects of insulin may be altered in favor of a pressor effect in patients with hypertension.

\section{Vasodilating Mechanisms of Insulin}

As mentioned above, insulin may cause peripheral vasodilation in some normotensive subjects. We determined the role of the endothelium in insulin-induced vasodilation in young healthy volunteers. Intra-arterial infusion of insulin increased forearm blood flow from $4.9 \pm 1.7$ at rest to $5.9 \pm 1.8 \mathrm{ml} / \mathrm{min} /$ $100 \mathrm{ml}$ and increased 6-keto prostaglandin $\mathrm{F}_{1 \alpha}$ (a metabolite of prostacyclin) in the venous effluents from $14.9 \pm 3.3$ to $29.3 \pm 5.7 \mathrm{pg} / \mathrm{ml}$. Indomethacin (75 mg, P.O) abolished insulin-induced vasodilation and increases in prostaglandin $\mathrm{F}_{1 \alpha}$. Intra-arterial infusion of L-NMMA (a blocker of oxide synthesis) caused marked vasoconstriction but did not affect insulin-induced vasodilation. Our results may suggest that insulin-induced vasodilation is mediated by prostacyclin but not by nitric oxide in the forearm of healthy humans. Although we did not examine the role of endothelium in control of peripheral circulation by insulin in hypertensive subjects, it is 


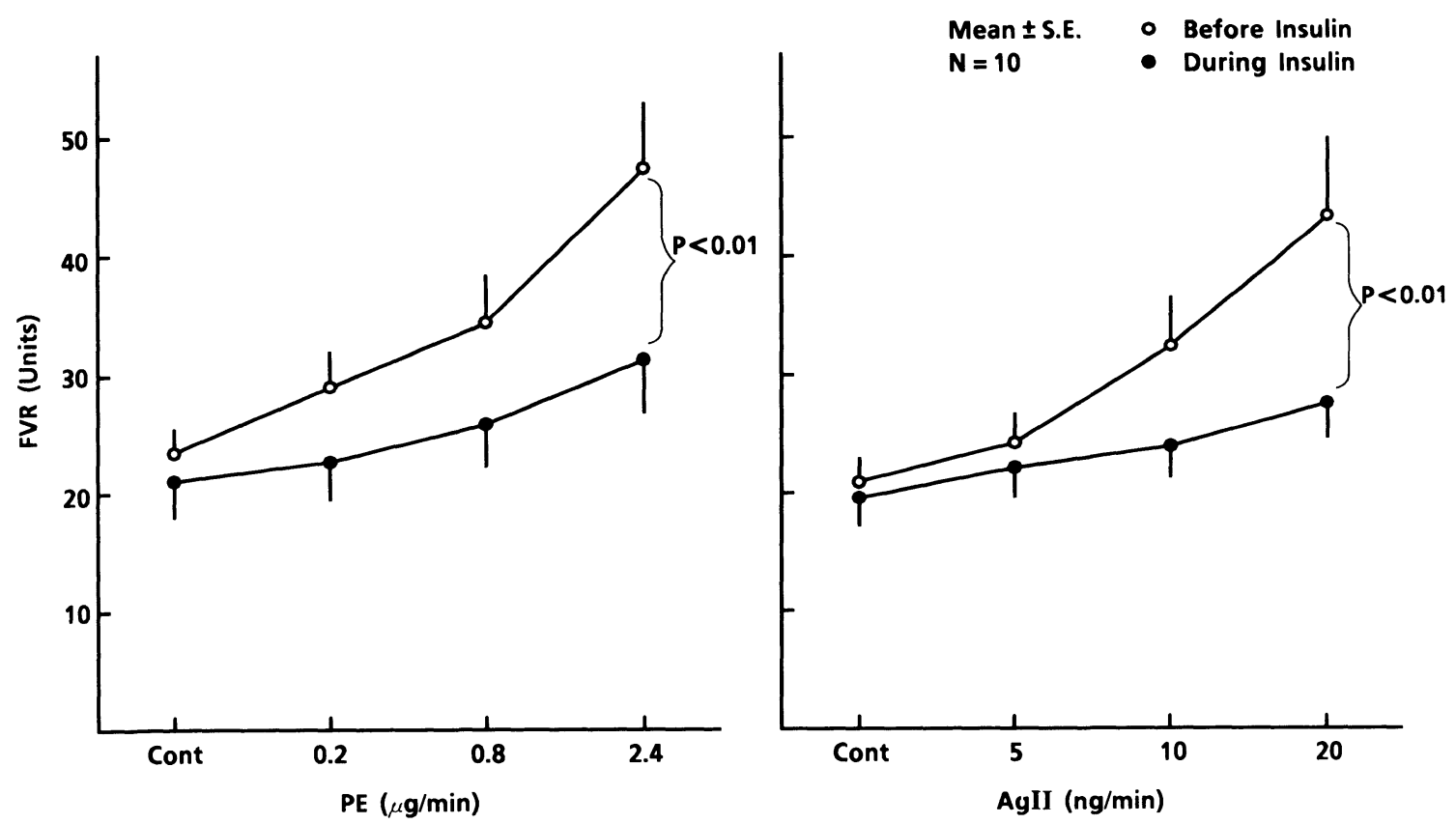

Fig. 2. Line graphs show changes in forearm vascular resistance (FVR) evoked by intra-arterial infusion of graded doses of phenylephrine (PE) (left panel) and of angiotensin II (Ang II) (right panel). Note that vasoconstrictor responses to drugs were attenuated during insulin infusion. Cont, control. From ref. 9.

\section{Case ( W.J 32yo )}

\section{Control}

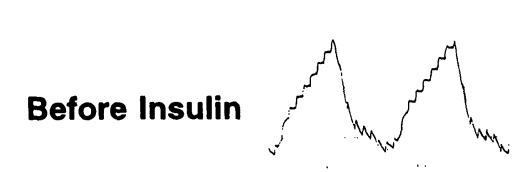

FBF (ml/min/100ml)
4.8
4.7

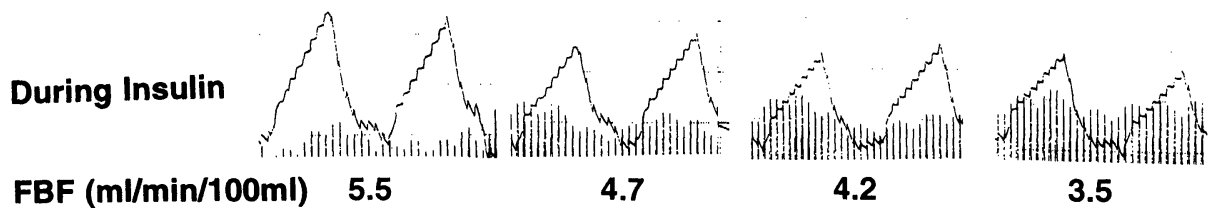

Angiotensin II ( $\mathrm{ng} / \mathrm{min}$ )

5

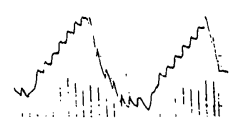

3.9
10

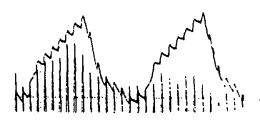

3.5
20

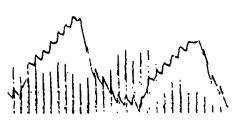

3.4

Fig. 3. These figures show representative plethysmographic recordings of forearm blood flow in a subject in response to intra-arterial infusion of angiotensin II at graded doses before (upper figures) and during (lower figures) simultaneous infusion of insulin at a rate of $0.15 \mathrm{mU} / \mathrm{kg}$ per min. Angiotensin II decreases forearm blood flow dose-dependently during insulin infusion, as well as in the control state during saline infusion. FBF, forearm blood flow. From ref. 19.

possible that endothelial dysfunction in hypertension may impair insulin-induced vasodilation. Furthermore, impaired endothelial function may contribute to loss of anti-vasoconstricting effects of insulin, resulting in vasoconstriction in response to pressor stimuli.

\section{Conclusion}

In summary, local hyperinsulinemia at physiological levels during intra-arterial infusion of insulin causes vasodilation in some healthy young subjects but not in all, and attenuates vascular reactivity to pressor stimuli in healthy young subjects. These may be mechanisms by which intravenous infusion of insulin dose not elevate blood pressure in normotensive subjects despite its sympathetic activation. In contrast, the anti-vasoconstricting effects of insulin are lost in hypertensive subjects which may contribute to the development and maintenance of hypertension. 


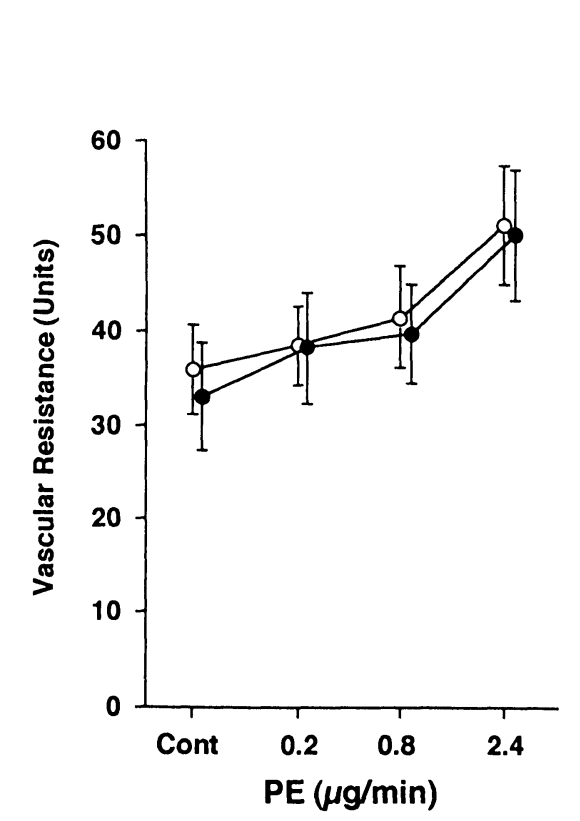

$\begin{array}{lll}\operatorname{mean}_{\mathrm{n}=7} \mathrm{SEM} & \text { Before Insulin } \\ & \text { During Insulin }\end{array}$

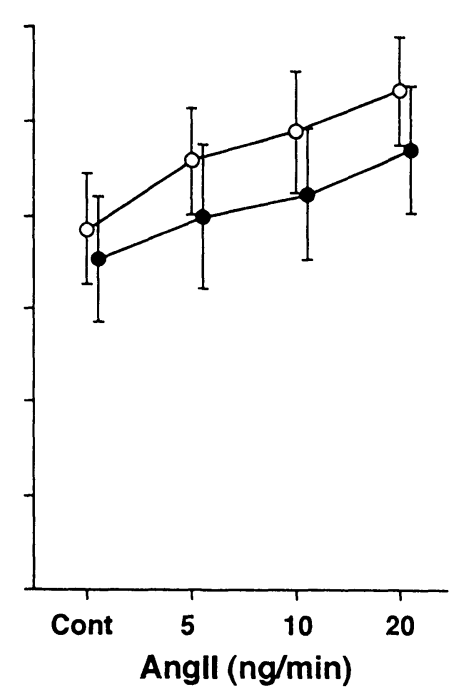

Fig. 4. Line graphs show changes in forearm vascular resistance evoked by intra-arterial infusion of graded doses of phenylephrine (left panel) and of angiotensin II (right panel). Both phenylephrine and angiotensin II increases forearm vascular resistance dose-dependently during intra-arterial infusion of insulin, as well as before insulin infusion. cont, control. Means \pm SEM. From ref. 19.

\section{References}

1. Ferrannini E, Buzzigoli G, Bonadonna R, et al: Insulin resistance in essential hypertension. $N$ Engl $J$ Med 1987; 317: 350-357.

2. Lucas CP, Estingarribia JA, Darga LL, Reaven GM: Insulin and blood pressure. Hypertension 1985; 7: 702-706.

3. Baron AD, Brechtel-Hook G, Johnson A, Hardin D: Skeletal muscle blood flow. A possible link between insulin resistance and blood pressure. Hypertension 1993; 21: 129-135.

4. Lembo G, Napoli R, Capaldo B, et al: Abnormal sympathetic overactivity evoked by insulin in the skeletal muscle of patients with essential hypertension. J Clin Invest 1992; 90: 24-29.

5. Rowe JW, Young JB, Minaker KL, Stevens AL, Pallotta J, Landsberg L: Effect of insulin and glucose infusion on sympathetic nervous system activity in normal man. Diabetes 1981; 30: 219-225.

6. Anderson EA, Hoffman RP, Balon TW, Sinkey CA, Mark AL: Hyperinsulinemia produces both sympathetic neural activation and vasodilation in normal humans. J Clin Invest 1991; 87: 2246-2252.

7. Liang CS, Doherty JU, Faillace R, et al: Insulin infusion in conscious dog. J Clin Invest 1982; 69: 13211336.

8. Laakso M, Edelman SV, Brechtel EG, Baron AD: Decreased effects of insulin to stimulate skeletal muscle blood flow in obese man. J Clin Invest 1990; 85: 1852-1884.

9. Sakai K, Imaizumi T, Masaki H, Takeshita A: Intraarterial infusion of insulin attenuate vasoreactivity in human forearm. Hypertension 1993; 22: 735-742.

10. Lembo $G$, Rendina $V$, Iaccarino $G$, Lamenza $F$, Volpe M, Trimarco B: Insulin reduces reflex forearm sympathetic vasoconstriction in healthy humans. Hypertension 1993; 21: 1015-1019.

11. Ferrari P, Weidmann P: Editorial review. Insulin, insulin sensitivity and hypertension. J Hypertens 1991; 8: 491-500.

12. Scotto AR, Bennet T, Macdonald IA: Effects of hyperinsulinemia on the cardiovascular responses to graded hypovolemia in normal and diabetic subjects. Clin Sci 1988; 75: 85-92.

13. Creager MA, Liang CS, Coffman JD: Betaadrenergic mediated vasodilator response to insulin in the human forearm. J Pharmacol Exp Ther 1985; 235: 709-714.

14. Gelfand RA, Barett EJ: Effect of physiological hyperinsulinemia on skeletal muscle protein synthesis and breakdown in man. J Clin Invest 1987; 80: 1-6.

15. Natali A, Buzigoli G, Taddei S, et al: Effects of insulin on hemodynamics and metabolism in human forearm. Diabetes 1990; 39: 490-500.

16. Yamamoto M, Takata S, Yagi S, et al: Effects of insulin on pressor responsiveness and baroreflex function in diabetes mellitus. Jpn Circ J 1986; 50: 943948.

17. Vierhapper H, Waldhausl W, Nowotny P: The effect of insulin on the rise in blood pressure and plasma aldosterone after angiotensin II in normal man. Clin Sci 1983; 64: 383-386.

18. Gans ROB, Bilo HJG, Maarschlkerweerd WWAV, Heine RJ, Nauta JJP, Donker AJM: Exogenous insulin augments in healthy volunteers the cardiovascular reactivity to noradrenaline but not to angiotensin II. J Clin Invest 1991; 88: 512-518.

19. Fujishima S, Imaizumi $\mathrm{T}$, Abe S, Takeshita A, Fujishima M: Effects of intra-arterial infusion of insulin on forearm vasoreactivity in hypertensive humans. Hypertens Res 1995; 18: 227-233. 